\title{
Bioethanol and Residual Glucose from Filtrate Bamboo with Micro Controlller of Speed at Fermentation Process
}

\author{
Ni Ketut Sari ${ }^{1, *}$, Intan Yuniar Purbasari ${ }^{2}$, Basuki Rahmat ${ }^{2}$ \\ ${ }^{I}$ Dept. Chemical Engineering, Universitas Pembangunan Nasional Veteran Jawa Timur, Surabaya, Indonesia \\ ${ }^{2}$ Dept. Informatic, Universitas Pembangunan Nasional Veteran Jawa Timur, Surabaya, Indonesia \\ *Corresponding author. Email: ketutsari.tk@upnjatim.ac.id
}

\begin{abstract}
The need for bioethanol each year increases steadily while raw materials tend to decline, this is due to bioethanol raw materials, so sought after materials that can be regenerated, bamboo is one of the alternative raw materials, Bamboo has a cellulose content ranging from 42.4\%-53.6\%. The chemical process in bioethanol cultivation includes the process of pretreatment, delignification, hydrolysis, and fermentation, it equipped with a micro-type controller Arduino with a fuzzy method using Delphi. Research results in the form of speed profiles, residual glucose levels, bioethanol function fermentation time. Fermentation time with fermiol optimum at 6 days, the highest yield of bioethanol 31.7\%, the highest residual glucose concentration $3.9 \%$, filtrate bamboo $250 \mathrm{ml}$. Result of running the Arduino type Controller microprogram with the fuzzy method using the Delphi language at the time of 137 seconds with a set point of $970 \mathrm{C}$, as a result of running a comparison program from two controllers IE Auto-tuning PID with overshot $217(0.08)$ slurries Time 5.26 and PID ACO with overshot 202 (0.018) slurries time 0.55 seconds. Of these two controllers can be selected PID ACO as the best controller with the fastest slurries time and the overshot is quite small.
\end{abstract}

Keywords: bamboo, fuzzy method, hydrolysis, residual glucose

\section{INTRODUCTION}

Bamboo contains a high enough cellulose composition, thus potentially as the raw material of bioethanol, before the fermentation process, first carried out the process of pre-treatment, delignification and hydrolysis, for the process of pre-treatment and delignification obtained reduction of the composition of lignin and Pentosane, for the chemical hydrolysis process $(\mathrm{H}-\mathrm{Cl})$ and biology (cellulose enzymes) produced a glucose level of 23, 6\% [1]. In the chemical hydrolysis process (ammonia acid) [2], sodium chloride [3], dilute sulfuric acid in the removal of hemi lignocellulose [4].

In the chemical hydrolysis process $(\mathrm{H}-\mathrm{Cl})$, using the microtype Arduino UNO controller, optimization of cellulose levels function hydrolysis time is $18.7 \%$ and of glucose levels function hydrolysis time is $23.6 \%$ [5]. An effective process in the process of converting biomass to glucose is Pretreatment, to enhance the ability of the surface area (porosity) of cellulose so as to increase the conversion of cellulose into glucose, while also eliminating Lignin and hemicellulose, levels of cellulose crystals [6].

Availability of cellulose (bamboo) is available in large quantities in Indonesia. Bamboo is used in the hydrolysis process which does not contain lignin and pentose that previously performed pretreatment. The results of the hydrolysis process produce glucose as the raw material for bioethanol, biological processes or chemical processes using $\mathrm{Na}-\mathrm{OH}, \mathrm{H}-\mathrm{CL}$, and $\mathrm{H}_{2} \mathrm{SO}_{4}$ that can optimize glucose production. Filtrate that does not contain lignin, generated glucose from the hydrolysis process, for liquid rice flour contains $9.98 \%$ glucose, bulrushes contains $37.9 \%$, and bamboo contains $23.6 \%$ glucose [7].

Bamboo contains cellulose, reduce the amount of lignin and pentose pretreatment process and not lignin, filtrate glucose produced in the fermentation using enzymes cellulose, the process of fermentation obtained bioethanol levels (18-22) \% [8]. The production of bioethanol in simulations with process fermentation using the Mat-lab programming, which the graphs the results using excel tool, less effective and efficient, so for the visualization needed programming languages object-oriented, in addition to naturally developed at, the other has the advantage in a software project can use various programming languages that support object-oriented programming [9].

PID controllers used control applications because of its simple structure and control algorithms are easy. Design of control model using PID control tuning with auto-tuning PID mat-lab, which tuning with Ant Colony Optimization (ACO) to control the speed of a DC motor, is expected to have steady-state error, settling time and overshoot. Model speed control using PID-ACO was found to have faults steady-state, continuous and overshoot time better than PID Auto-tuning Mat-lab. The result of the PID-ACO programs in this study is the best controller with the fastest time of about 0.55 seconds and overshot the smallest 1.017 [10]. 
An Integral Proportional control system on Derivative (PID) when made very sensitive, then the system response against disturbance produces mostly undershot/overshot, so the higher oscillation occurs. In PID control system with fuzzy logic to minimize overshoot and undershot time from the system response. A significant output of the fuzzy logic control system is only $50 \%$ of PID control. From the design of the system is expected in the overall control system which is a hybrid between PID Control with Fuzzy logic can produce a better system response [11]. Conducted a research with the title "Fuzzy Hybrid Control application-PID Motor Speed induction for prototype-based Pico Hydro power plant" that control speed rotation of motor induction using PID-Fuzzy algorithm has succeeded Done. The results showed an induction motor when the load changed its rotation to the value of the set point (Error 0\%), while the control response of PID-Fuzzy Hybrid resulted in under shoot faster than the control of PID but without oscillation with Slurries Time 1 second.

The production of bioethanol and residual glucose from bamboo is experimental research furnished the application technology of micro controller the Arduino UNO types in speed fermentation process

\section{METHODS}

Application technology of microcontroller PID temperature type of Arduino UNO for the production of glucose from bamboo by hydrolysis to obtain temperature profiles against hydrolysis time retrieved precise and accurate results. With this application, it will be extracted the right temperature range, during the process of hydrolysis of the already determined the temperature setpoint, temperature control with easy tools in the design process of hydrolysis.

\section{a. Application of PID in The Process Fermentation}

PID controllers used for motor control applications because of its simple structure and control algorithms are easy to understand. The parameters of the controllers generally use the Try and Error frequency response method or ZieglerNichols. This method has a successful outcome but quite a long time and to get a satisfactory system response. Intelligent control-based Artificial Intelligent (AI) has been developed to improve the conventional controls. Design of DC motor control model using some kinds of powers, i.e., the PID control tuning with mat-lab, the PID auto-tuning with Ant Colony Optimization (ACO) to control the speed of a DC motor, is expected to have steady state error, settling time and overshoot. DC motor output routed to invert input PID which further calculate substantial difference or mistake that is later used to improve PID constants.

PID control is a composite control system between the proportional control, integral, and derivative, the application of this method in a closed system, where the reference input function is a ladder (step). Controllers used proportional controllers $(\mathrm{Kp})$, raised from 0 to a critical value of proportional controllers, so gained output that continually oscillates with the same amplitude, critical appraisals of proportional controllers called ultimate gain. The amount of the final period, obtained after the production of the system achieve continuous oscillation conditions.

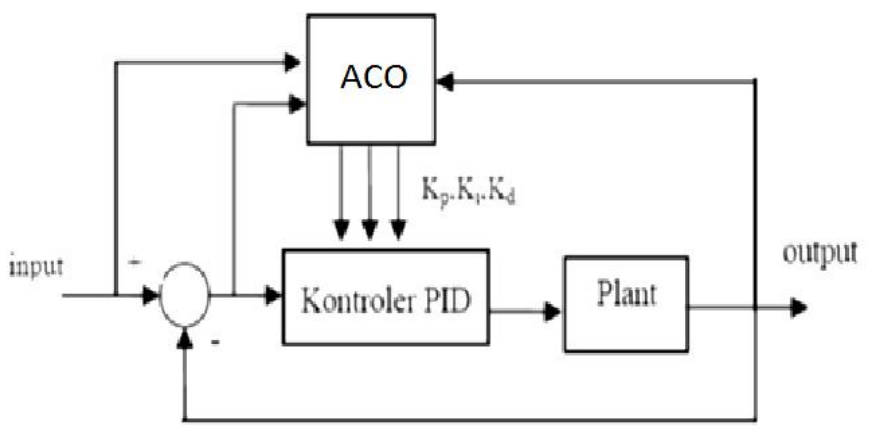

Figure 1. Controller PID-ACO for plant

Common characteristics used in the control of such a system include the stability, accuracy, speed of response and sensitivity [12]. Proportional control in action, the output of the control system necessarily proportional to its input. The output signal is the strengthening of a signal fault with specific factors, and it is strengthening proportional factor and constant of the system, which expressed with a factor proportional, where factor proportional has a high response/quick. Integral control in action, the output of the controller is continually changing throughout the deviation, and the speed of change of the production is proportional to error, its constant declared (Ki), where it has a high sensitivity, by way of the reduction of error resulting from the feedback signal. The high the value of Ki so sensitivity will be higher, but the time required to achieve stability faster, and vice versa. While the action control of the derivative works based on the rate of change of the junction, so the type of the controller is always used together with proportional and integral controller, its constant declared $(\mathrm{Kd})$, where it affects the stability of the system, due to the action of this control can reduce errors.

$$
\begin{aligned}
& \mathrm{D}=\mathrm{Kpe}(\mathrm{t})+\mathrm{Ki} \int \mathrm{e}(\mathrm{t}) \mathrm{dt}+\mathrm{Kd} \frac{\mathrm{de}(\mathrm{t}]}{\mathrm{dt}} \\
& P_{\text {Term }}=K p e(t) \\
& \mathrm{I}_{\text {Term }}=\mathrm{Kt} \int \mathrm{e}(\mathrm{t}) \mathrm{dt} \\
& \mathrm{D}_{\text {Term }}=\mathrm{Kd} \frac{\mathrm{de}(\mathrm{t})}{\mathrm{dt}}
\end{aligned}
$$

The sensor is a digital sensor DS18B20 has 12-bit internal ADC, high precision with reference voltage of 5 volts, the smallest change in temperature equates 0.0012 volts, in the temperature range -10 to +85 degrees Celsius, sensor DS18B20 has the sensor accuracy is $+/-0.5$ degrees, the sensor works using the 1-wire communication protocol (one-wire). 


\section{b. Experiment Process of Fermentation}

The pieces and refined fiber of bamboo with an approximate length of $5 \mathrm{~cm}$ and polished thread 200 mesh were to obtain the high levels of glucose and cellulose before bacillus, and the $\mathrm{H}-\mathrm{Cl}$ solution hydrolyzed it. It should in powder form so that cellulose hydrolyzed perfectly. However, that process took a higher cost. Besides, bulrush in the powder form could suffer physical destruction, thus causing the damage of the glucose group. The drying process of bulrush was naturally done first in the room temperature. The drying process was done in an oven at $100{ }^{\circ} \mathrm{C}$ for 3 hours.

It was for cost savings, and the dryer process aimed to reduce the water content in ethanol. The water level that was permitted by Standart National Indonesia (SNI) was $1 \%$. The decreasing of $\mathrm{pH}$ from pretreatment material was affected by the addition of $\mathrm{H}-\mathrm{Cl}$ volume $7 \% \mathrm{v} / \mathrm{v}$ because the requiring $\mathrm{pH}$ for the fermentation process was 4,5 . Before doing the hydrolysis process, the $\mathrm{pH}$ of the filtrate measured according to the terms of the fermentation process that is approximately 4.5 , to obtain $\mathrm{pH} 4.5$, the addition of $\mathrm{Na}-\mathrm{OH}$ done if $\mathrm{pH}$ of the filtrate.

The production of bioethanol and residual glucose from filtrate bamboo with the fermentation process is experimental research furnished the application technology micro controller the Arduino UNO types in speed, with the study as follows:

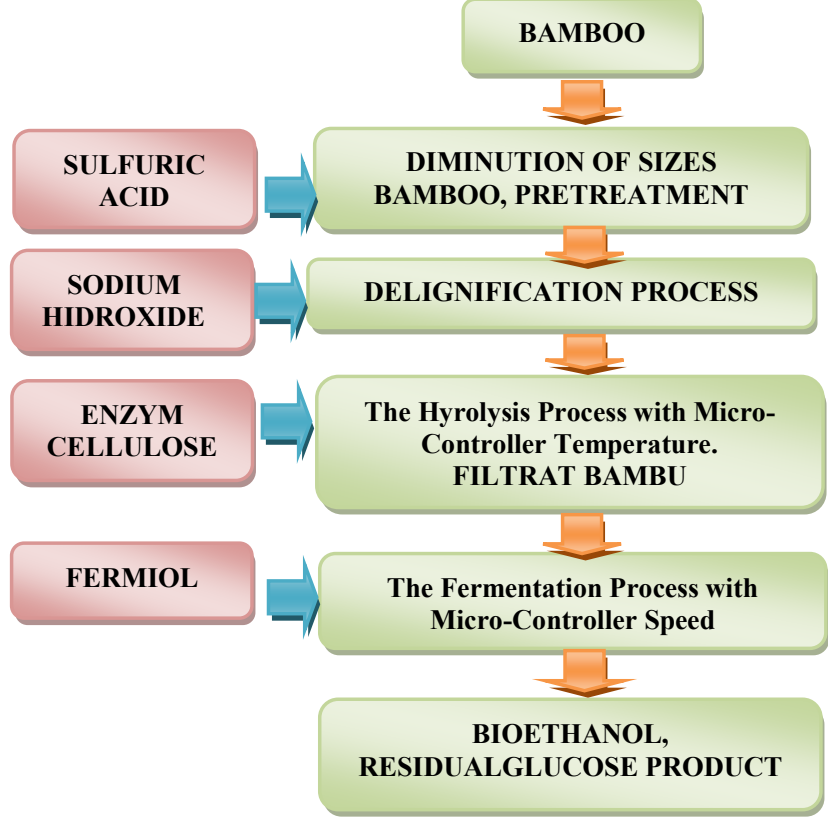

Figure 2. Block diagram of bioethanol and residual glucose production from filtrate bamboo with micro controller

The sensor is a digital sensor DS18B20 has 12-bit internal $\mathrm{ADC}$, high precision with reference voltage of 5 volts, the smallest change in temperature equates 0.0012 volts, in the temperature range -10 to +85 degrees Celsius, sensor DS18B20 has the sensor accuracy is $+/-0.5$ degrees, the sensor works using the 1-wire communication protocol (one-wire).

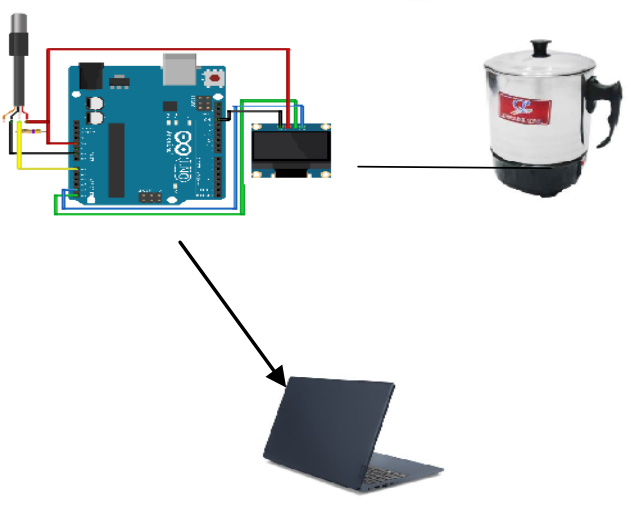

Figure 3. Configuration hardware of temperature sensor DS18B20

\section{RESULTS AND DISCUSSION}

In Figure 4 on a volume fermiol, residual glucose concentration maximum $3.9 \%$ on-trend on large filtrate bamboo $250 \mathrm{ml}$, maximum levels obtained from the cellulose of wood $18.7 \%$. The results obtained allows the bamboo can be as the raw material alternative to bioethanol. Several factors that encourage research utilization intensive do lignocellulose materials into a source of energy, in this case, ethanol [12]. First, the needs and energy consumption continued to increase from year to year, while natural resources which can generate energy-depleted because most of the current sources of energy derived from natural resources that are not renewable, such as oil, gas, and coal. Second, bioethanol has better characteristics compared to gasoline because it can increase the efficiency of combustion [13].

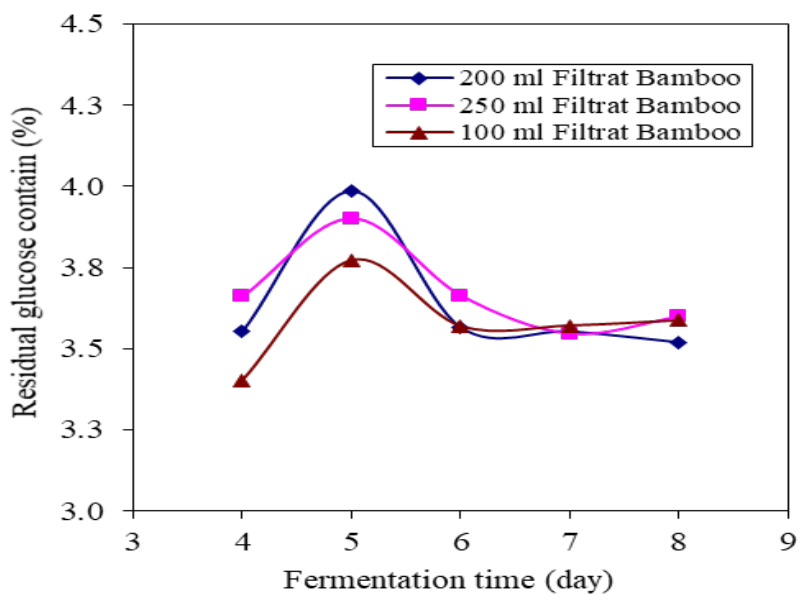

Figure 4. Contains of residual glucose function time fermentation 


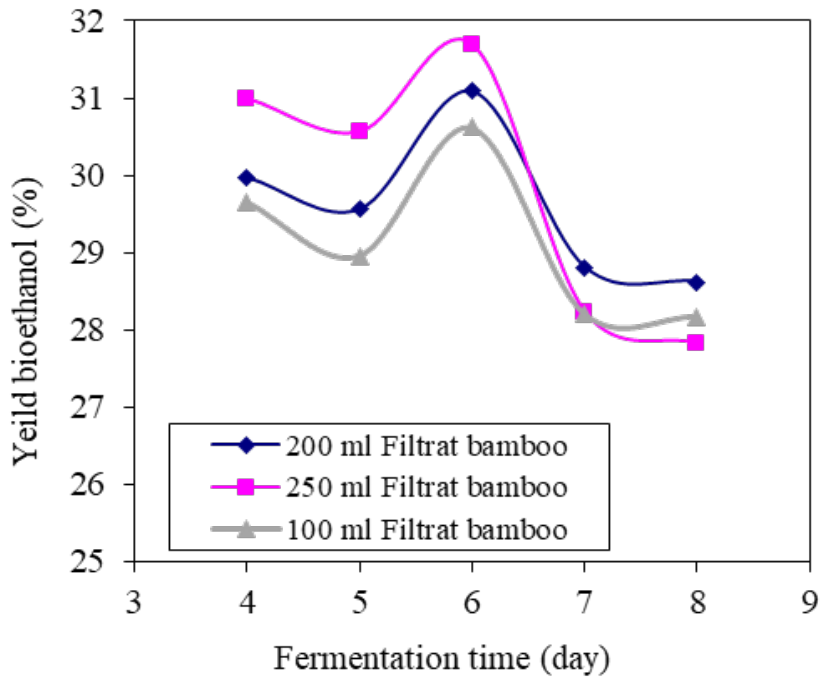

Figure 5. Contains of bioethanol function time fermentation

In Figure 5 on a volume fermiol, $250 \mathrm{ml}$ filtrate bamboo, maximum levels obtained from the yield bioethanol $31.7 \%$. The results obtained allows the bamboo can be as the raw material alternative to bioethanol. Several factors that encourage research utilization intensive do lignocellulose materials into a source of energy, in this case, ethanol [13]. First, the needs and energy consumption continued to increase from year to year, while natural resources which can generate energydepleted because most of the current sources of energy derived from natural resources that are not renewable, such as oil, gas, and coal. Second, bioethanol has better characteristics compared to gasoline because it can increase the efficiency of combustion [14].

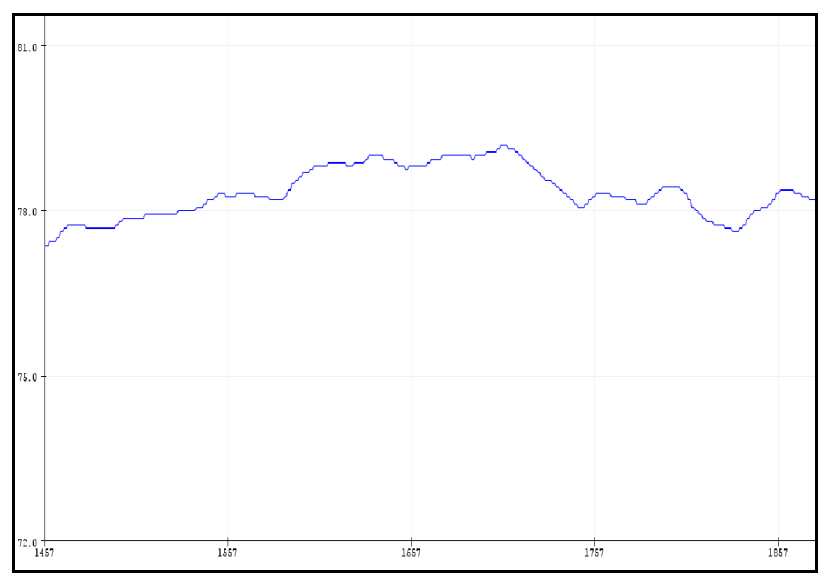

Figure 6. Test result contains of bioethanol function time fermentation

At the time of 14 seconds, setpoint $97{ }^{\circ} \mathrm{C}$, the action control and error show the temperature below $10{ }^{\circ} \mathrm{C}$ and the temperature of the measured $94.696{ }^{0} \mathrm{C}$. With the passage of time will be retrieved according to temperature setpoint, such as Figure 6 . At the time of 20 seconds, the setpoint $97{ }^{\circ} \mathrm{C}$ shows the action control, and error shows the temperature under $0{ }^{\circ} \mathrm{C}$ and the measured temperature is $96.59{ }^{0} \mathrm{C}$, with time will be retrieved according to the temperature set point. At the time of 137 seconds, setpoint $97{ }^{0} \mathrm{C}$ shows the action control and error shows the temperature under $0{ }^{\circ} \mathrm{C}$ and the measured temperature is 97 ${ }^{0} \mathrm{C}$ as Figure 5. Microtechnology an Integral Proportional temperature Derivative controller type Arduino UNO using the Fuzzy method can use as a reference in the design of the excellent hydrolysis process tools.

The result of using a Fuzzy PID indicates that the results can be more stable and a smaller received error type using a fuzzy and the results gained when using the Fuzzy PID are in numbers 78 to 78.2 degrees. This indicates that the fuzzy use of the program makes the oscillation more stable and lowers the error value so that the error gets smaller by 0.2 degrees. The addition of the fuzzy method with the PID value set to the lowest error with the existing PID constants can reduce the error, the test is done several times to monitor the difference. From the results that get the fuzzy additions help the temperature setting more stable as well as a reduced error or overshoot that was originally in the number 0.6 to about 0.3 degrees Celsius.

\section{CONCLUSION}

The hybrid control system capable of generating a response and recovery time is better and resistant to disturbance, is evident from the results of testing the system with the awarding of the disorder, an occurrence of undershoot and overshoot of the granting of discharge loads and load can be mute. To get a good response on the hybrid PID control system -the Fuzzy method can be done tuning evaluation rules as well as the membership function value to widen the way crisp input, with the aim to dampen overshot.

At the time of 137 seconds, setpoint $97{ }^{\circ} \mathrm{C}$ shows the action control and error shows the temperature under $0{ }^{\circ} \mathrm{C}$ and the measured temperature is $97{ }^{0} \mathrm{C}$. Micro-technology an Integral Proportional temperature Derivative controller type Arduino UNO using the control of Fuzzy, can be used as a reference in the design of the excellent hydrolysis process tools at optimization of the cellulose levels function hydrolysis time is $18.7 \%$, and the optimization of the residual glucose levels function fermentation time is $3.9 \%$, and yield bioethanol function fermentation time is $31.7 \%$.

\section{ACKNOWLEDGMENT}

The authors would like to acknowledge the financial support of the Directorate Research and Public Service. The Directorate of Research and Development Strengthening. The Ministry of Research, Technology, and Higher Education of the Republic of Indonesia with the Research-Based Competence Grant. Contract Number: 083/SP2H/LT/DRPM/2018. 


\section{REFERENCES}

[1] N.K. Sari, Y. Nico, L. Tika, and E. Dira, Hydrolysis of Cellulose from Bamboo with Biology Process Using Enzyme, Journal Advanced Science Letters, vol. 23, no. 12, 2017, pp. 12235 12238.

[2] F. Teymouri, L.L. Peres, Alizadeh, and B.E. Dale, Optimization of the Ammonia Fiber Explosion (AFEX) Treatment Parameters for Enzymatic Hydrolysis of Corn Stover, Bio-resource Tech., vol. 96, 2005, pp. 2014-2018.

[3] A. Kumar, L.K. Singh, and S. Ghose, Bioconversion of Lignocellulose Fraction of Water-Hyacinth (Eichhornia) Hemicellulose Acid Crassipes Hydrolysate to Ethanol by Pichia Stipilis, Bioresource Technology, vol. 100, 2009, pp. 32933297.

[4] N.K. Sari, S. Sutiyono, E. Luluk, E. Dira, W. Putu, and S.H. Tatik, Bioethanol Production from Liquid Waste of Rise Flour with Batch Process, Proceeding MATEC Web of Conference, vol. 58, no. 01003, 2016, pp. 1-5.

[5] N.K. Sari, D. Ernawati, I.Y. Purbasari, B. Rahmat, Hydrolysis of Glucose from Bamboo with Micro Controller PID type Arduino UNO and Fuzzy Method, Proceeding Atlantis Highlights in Engineering, vol. 1, 2018, pp. 35-39.

[6] J.S. Lee, B. Parameswaran, J.P. Lee, and S.C. Park, Recent Development of Crusial Technologies On Cellulosic Ethanol Production, Journal of Scientific and Industrial Research, vol. 67, no. 11, 2008, pp. 965-873.

[7] N.K. Sari, Pudjiastuti, and Ketut Sumada, Comparison Production Glucose from Starch and Cellulose Using Delignification Hydrolysis Process, vol. 23 , no. 12 , 2017, pp. 12318-12321.
[8] N.K. Sari and E. Dira, Comparison Production Bioethanol from Cellulose using Batch Distillation and Flash Distillation Process, Journal of GEOMATE vol. 15, no 50, 2018, pp. 76-81.

[9] N.K. Sari, C. Pujiastuti, I. Nyoman Abdi, Bioethanol Production Comparison of Elephant Grass and Liquid Waste Plant Wheat Boga Sari, Internasional Seminar on Chemical Engineering Bio-Energy, Chemicals and Materials (BioEnChe 2013), ITB Bandung, Indonesia, ISSN 2354-5917, 2013, Module: BE.02, 2013.

[10] Mochammad Nur Masrukhan, Mochamad Piono Mulyo, Dwi Ajiatmo, and Machrus Ali, Optimization of Speed Motor DC Using PID with Tuning Ant Colony Optimization (ACO) Controller, Proceeding SENTIA ISSN: 2085-2347, Politeknik Negeri Malang, vol. 8, 2016, pp. B-49B-52.

[11] M. Samsul Bachri, Hybrid Control System of PIDFuzzy Logic on DC Motor Speed Settings, Makara Technology, vol. 8, no. 1, 2004, pp. 25-34.

Samsul Bachri M. 2004, Sistem Kendali Hybrid Pid - Logika Fuzzy Pada Pengaturan Kecepatan Motor DC, MAKARA, TEKNOLOGI, VOL. 8, NO. 1, hal. 25-34.

[12] J.M. Jacob, "Industrial Control Electronics Application and Design," Prentice Hall Inc. Englewood Cliffs, New Jersey, 1988.

[13] Nibedita Sarkar, K.G. Sumanta, Satarupa Bannerjee, Kaustav Aikat, Bioethanol Production from Agricultural Wastes: An Overview, Renewable Energy, vol. 37, 2012, pp. 19-27.

[14]A. Limayem and S.C. Ricke, Lignocellulosic Biomass for Bioethanol Production: Current Perspectives, Potential Issues, and Future Prospects, Progress Energy Combust. Sci., vol. 38, 2012, pp. 449-67. 